\title{
Acute health problems in African refugees
}

\section{Ten years' experience in a Swiss emergency department}

\author{
Carmen A. Pfortmueller, Fabienne Graf, Malek Tabarra, Gregor Lindner, \\ Heinz Zimmermann, Aristomenis K. Exadaktylos
}

Received: 9 April 2012 / Accepted: 16 July 2012 / Published online: 15 August 2012

(c) Springer-Verlag Wien 2012

Gesundheitsprobleme afrikanischer

Asylbewerber und Flüchtlinge - Zehn

Jahre Erfahrung aus einem Schweizer

Universitäts-Notfallzentrum

\section{Zusammenfassung}

Grundlagen In den letzten zwei Jahrzehnten haben die Asylanträge aus Afrika in den Ländern der Europäischen Union von 578.000 auf über 2,9 Millionen zugenommen. In der Schweiz kommen zirka $20 \%$ der Asylbewerber aus Afrika (7.196/36.100). Das Gesundheitsprofil dieser Bevölkerungsgruppe unterscheidet sich massgeblich von jenem im Asylland. Wir haben deshalb die Vorstellungsgründe afrikanischer Asylbewerber und Flüchtlinge an unserem Notfallzentrum untersucht.

Methodik Alle Daten wurden retrospektiv in unserem zentralen Patientenregister (SAP) erfasst. Alle Patienten, welche als Asylbewerber oder Flüchtling mit einem afrikanischen Ländercode registriert waren, wurden eingeschlossen. Die Studienperiode umfasste 01.01.2000 bis zum 30.11.2011. Erhoben wurden grundlegende demo-

A. K. Exadaktylos, M.D., F.C.E.M. ( $\square)$

Department of Emergency Medicine, University Hospital Bern, 3010 Bern, Switzerland

e-mail: exadaktylos@exadaktylos.ch

\section{A. Pfortmueller, M.D.}

Department of General Internal Medicine, Inselspital Bern, Bern, Switzerland

e-mail: cpfortmueller@gmail.com

F. Graf · M. Tabarra $\cdot$ G. Lindner $\cdot$ H. Zimmermann

Department of Emergency Medicine, Inselspital Bern, Bern,

Switzerland

e-mail: fabienne.graf@students.unibe.ch

M. Tabarra

e-mail: malektabbara@gmail.com

G. Lindner

e-mail: lindner.gregor@gmail.com

H. Zimmermann

e-mail: heinz.zimmermann@insel.ch graphische Daten (Alter, Geschlecht, Nationalität, Zivilstand, Religion) sowie das Vorstellungsdatum und den Vorstellungsgrund.

Ergebnisse Während der Studienperiode wurden insgesamt 3.675 afrikanische Asylbewerber oder Flüchtlinge auf unserem Notfallzentrum vorstellig. Vierunddreizig Prozent $(n=1.247)$ waren weiblich, $66 \%(n=2.426)$ waren männlich. Achtzig Prozent $(n=1.940)$ der Männer und $70 \%(n=823)$ der Frauen waren jünger als 40 Jahre. Die meisten Asylbewerber und Flüchtlinge kamen aus Algerien $(n=612)$, gefolgt von Somalien $(n=542)$ und Marokko $(n=286)$. Fünfundvierzig Prozent $(n=1.628)$ der Patienten hatten internistische Probleme, $40 \%$ $(n=1.487)$ Traumata und $8 \%(n=302)$ chirurgische Probleme. Dreieinhalb Prozent $(n=130)$ der Patienten litten an psychiatrischen Problemen. Die Vorstellungsrate aufgrund psychiatrischer Probleme hat von 2001 (2\%, $n=4)$ bis $2011(10 \%, n=35)$ stetig zugenommen.

Schlussfolgerung Die Vorstellungsgründe afrikanischer Asylbewerber und Flüchtlinge sind vielseitig. Der Schwerpunkt liegt bei internistischen Problemen und Traumata. Die Vorstellunghäufigkeit aufgrund psychiatrischer Probleme ist am Steigen. Weswegen die Etablierung einfacher Screening-Scores für posttraumatischen Stress gezielt gefördert werden soll.

\section{Schlüsselwörter: Asylbewerber, Flüchtling}

\section{Summary}

Background Over the last two decades, the total number of applications from Africans for asylum in the countries of the European Union has increased from 578,000 to more than 2.9 million. About $20 \%(7,196 / 36,100)$ of the asylum seekers in Switzerland originate from Africa. The disease profile of African asylum seekers is remarkably different from that of the native population in the country of application. We have therefore conducted an analysis of African asylum seekers presenting themselves to our emergency department.

Methods In a retrospective analysis, the central patient registry database was searched for patients origi- 
nating from Africa admitted from 1 January 2000 to 30 November 2011 and labelled as "Asylbewerber" (asylum seeker) or "Flüchtling" (refugee).

Results Three thousand six hundred and seventy-five African asylum seekers were admitted to our emergency department between 2000 and 2010. Thirty-four percent $(n=1,247)$ were female and $66 \%(n=2,426)$ male. Eighty percent $(n=1,940)$ of the men and $70 \%(n=823)$ of the women were younger than 40 years. Most of our patients originated from Algeria $(n=612)$. Forty-five percent $(n=1,628)$ of all patients presented with internal medical problems, $40 \%(n=1,487)$ with injuries. Three point five percent $(n=130)$ of all patients presented with psychiatric problems. Admission for psychiatric problems increased steadily from $2 \%(n=4)$ in 2001 to $10 \%$ $(n=35)$ in 2011 .

Conclusion The causes of presentation are manifold, including internal medical problems and injuries. Admissions for psychiatric problems are increasing. Establishing simple screening scores for somatization should be a key priority in providing more focused treatment in emergency departments.

Keywords: Asylum seeker, Health care use

\section{Introduction}

At the end of 2009, there were 43.3 million people worldwide who had been forcibly displaced due to conflict and persecution-the highest number since the mid 1990s [1]. Over the last two decades in the countries of the European Union, the total number of applications for asylum originating from Africa has increased from 578,000 to more than 2.9 million [2]. According to the United Nations High Commissioner for Refugees, 21 \% (210,6300 people) of all refugees worldwide originate from Africa [1]. National stability in Africa and worldwide is measured by the Failed States Index [3]. This index provides an overview of 12 indicators, such as refugee flows, poverty, security threats and especially public services such as health care [3]. Three African states (Somalia, Chad, Sudan) were the top ranking states on the Failed State Index in 2011 [3]. Somalia especially has been at the top end of the index since its invention in 2004 and since 2007 has been ranked each year as the least stable country in the world [4].

About $20 \%(7,196 / 36,100)$ of the asylum seekers in Switzerland originate from Africa $[5,6]$. For the duration of the asylum process, the Swiss government provides mandatory basic healthcare coverage [7]. All asylum seekers may register with a general practitioner free of charge [8].

Many African asylum seekers are physically and psychologically traumatized by war, war-like conditions and political or ethnic oppression [7]. Therefore their disease profile is strikingly different from that of the native population in the country of refuge [9]. Furthermore, acute and chronic healthcare problems may not only occur as the direct result of violence, but may also be due to the absence of a functioning and reliable health care system in their country of origin $[7,9]$.

Although the causes of migration flows and the effects of political policies have been much discussed, they have rarely been the subject of analysis in an emergency medicine context [2]. There have only been a few studies on the general health problems and the prevalence of diseases in African asylum seekers [7, 9-11]. There are virtually no data on the use of emergency department resources by African asylum seekers in Switzerland or central Europe. To our knowledge, this is the first study targeting this topic.

\section{Methods}

We are a level 1 interdisciplinary University Emergency Department, caring for two million people in the central region of Switzerland, and seeing about 35,000 patients per year.

All data were collected retrospectively using our central patient registry (SAP). All patients admitted to our emergency department are grouped and labelled according to their occupation and country of origin. The database was queried for patients admitted between 1 January 2000 and 30 November 2011. All patients labelled as "Asylbewerber" (asylum seekers) or "Flüchtling" (refugee) were searched by hand and their country code recorded. All patients with an African country of origin were included. Furthermore, baseline demographic data (age, gender, nationality, social relationship status, religion) were extracted, as well as the following clinical data: admission date, cause of presentation.

\section{Results}

A total of 3,675 asylum seekers were admitted to our emergency department during the study period. Thirtyfour percent $(34 \%, n=1,247)$ were female, $66 \%(n=2,426)$ male. An increase in the annual number of patients was recorded between 2000 and 2011 (3\% in $2000(n=116)$; $10 \%$ in $2011(n=348)$ ) (Fig. 1). From 2000 to 2011 , the proportion of male patients increased $(2000=59 \%, n=68$; $2011=70 \%, n=244$ ), whereas the proportion of female patients decreased $(2000=41 \%, n=48 ; 2011=30 \%$, $n=104)$. Eighty percent $(80 \%, n=1,940)$ of men and $70 \%$ $(n=823)$ of women were younger than 40 years. Men were younger than women, with $47 \%(n=1,140 / 2,426)$ of all males younger than 30 years, versus $36 \%(n=448 / 1,247)$ of all females (Fig. 2). Thirty-five percent (35\%, $n=1,172)$ of the patients were Muslim, $16 \%(n=531)$ Christian. The remaining patients $(49 \%, n=1,972)$ provided no data on religion. Forty-four percent $(44 \%, n=1,617)$ of all patients were single, whereas $32.5 \%(n=1,194)$ reported that they were married. Fifty-three percent $(n=1,289)$ of males and $26 \%(n=330)$ of females were single. In contrast, $50 \%(n=618)$ of females were married, compared to $24 \%(n=576)$ of males (Fig. 3$)$. Most of our patients originated from Algeria $(n=612)$, followed in frequency 
Fig. 1 Annual number of patients $\left(n_{\text {total }}=3,675\right)$ between 2000 and 2011

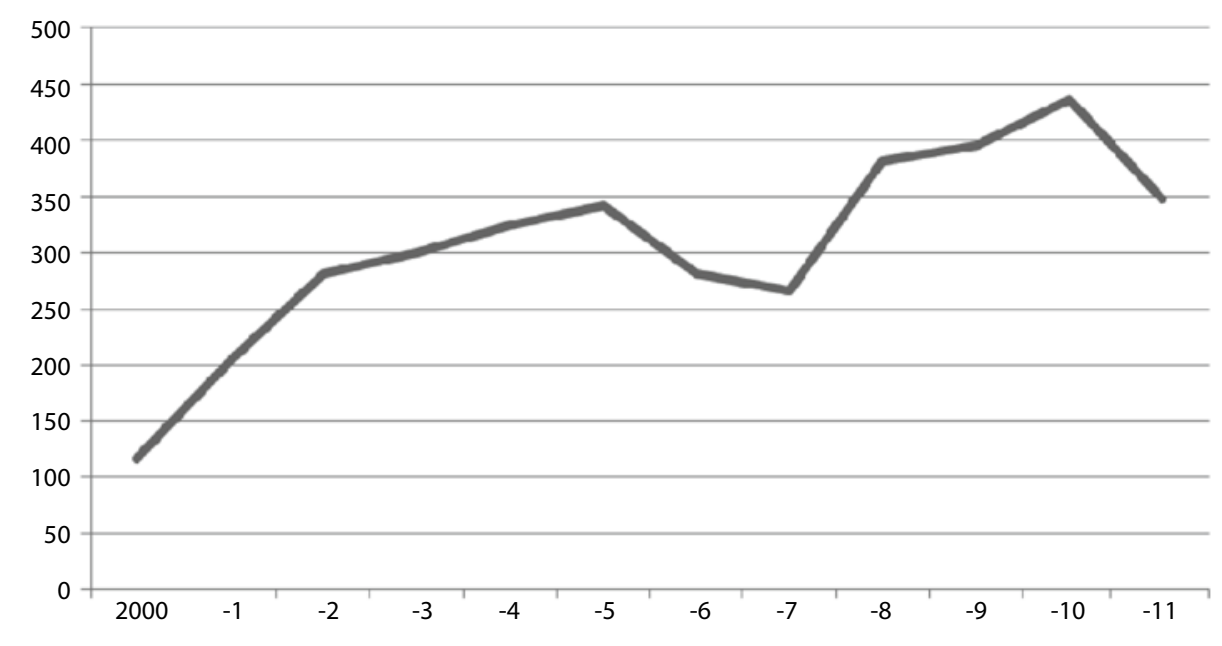

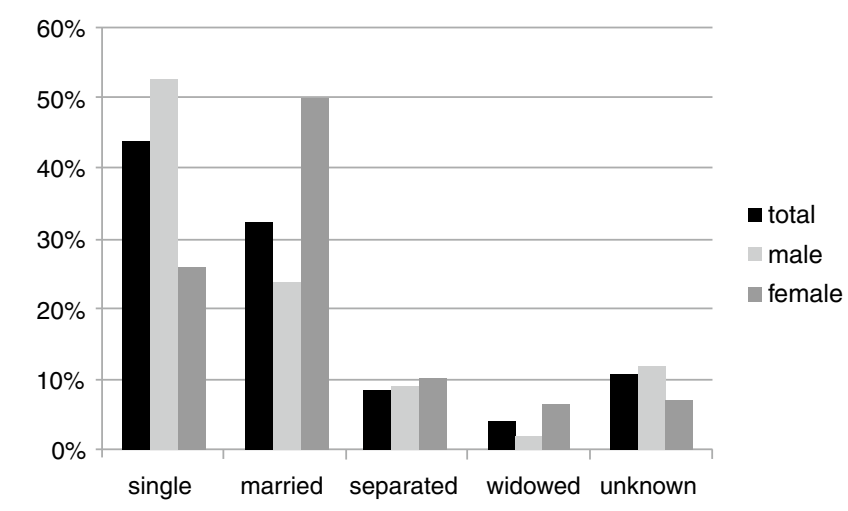

Fig. 3 Marital status: gender distribution

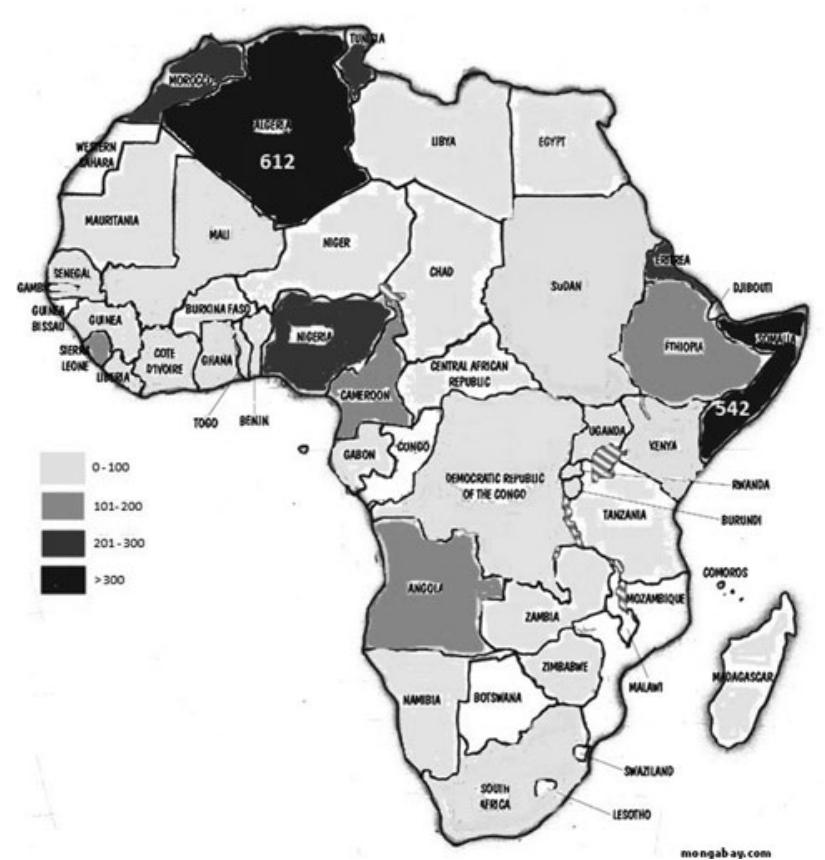

Fig. 4 Frequency of countries of origin overall 2000-2011

Admissions of African asylum seekers to our emergency department are increasing, but remain a small fraction of our patient population ( $1 \%)$. 
Fig. 5 Causes of admission

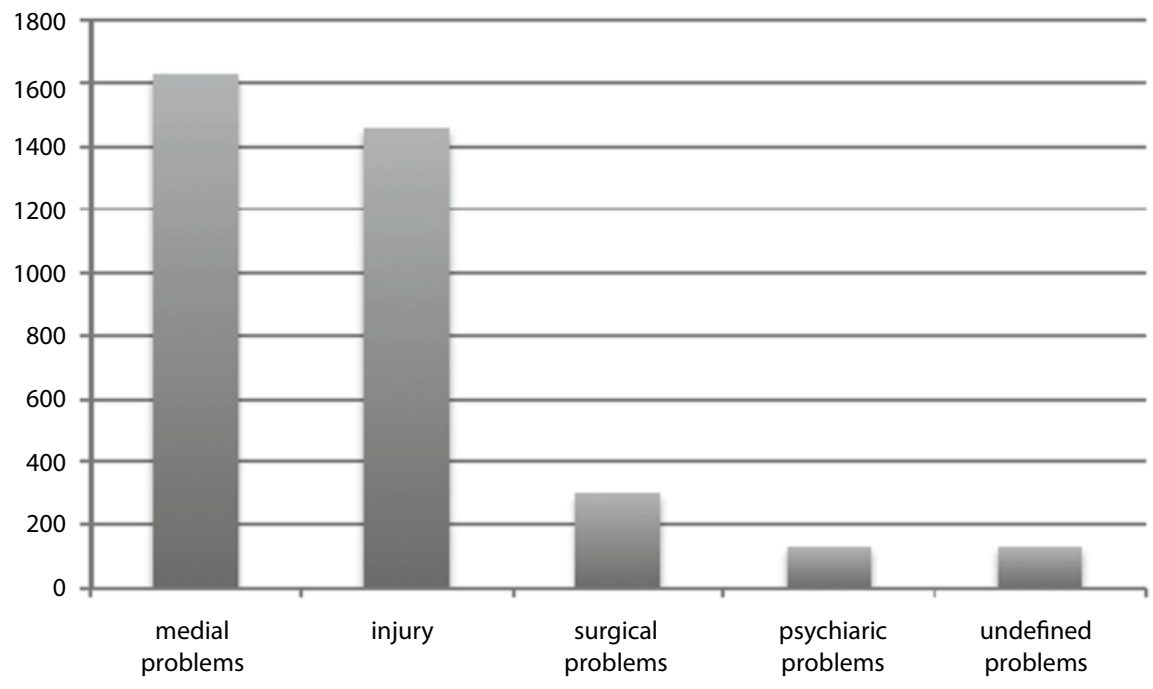

One possible explanation for the increasing absolute numbers of African asylum seekers admitted to our emergency department could be the general increase in the number of African asylum seekers admitted to Switzerland [6]. Overall numbers in Switzerland started at 7,990 asylum seekers in 2000 , rising to 11,614 asylum seekers in 2011 [6]. In relation to the figures for the whole country, the admissions to our emergency department have stayed stable ( $3.5 \%$ in 2002 to $3.48 \%$ in 2011). Therefore the increase in actual numbers we detected may be a reflection of the general increase in African asylum seekers in Switzerland and not due to any increase in the health care problems afflicting African asylum seekers.

In our study, we found that two thirds of our African asylum seekers are men. A study by Westermeyer et al. on Somali refugees confirms our findings [12]. Some studies on a mixed group of asylum seekers also found results similar to our study [6-9]. In our study, most of the patients were young, with a peak in the second and third decade of life. In a study by Harris and Telfer in which most of the subjects originated from Africa, the mean age was 33.5 years (range 15.9-68 years), a finding that is comparable with our results [8]. Our findings are also supported by the Federal Agency of Immigration [6]. In contrast, an Australian study on asylum seekers from Persia found a mean age of 42 years [13], which is older than we found. It may therefore be that African asylum seekers are younger than other groups of asylum seekers.

Single men are the most frequent group of African asylum seekers, a finding that is supported by other studies with asylum seekers from different countries [6, 7, 14]. In our study, African asylum seekers most often originated from Algeria, followed by Somalia, Tunisia, Morocco and Eritrea. According to O'Donnell et al. in Great Britain most asylum seekers from Africa originate from Somalia or Eritrea [15], a finding which is partly reflected by our study. According to the Federal Agency of Immigration, the top ranking countries of origin of African asylum seekers in 2011 were Eritrea, followed in frequency by Tunisia, Nigeria, Somalia and Algeria [6]. The peak of asylum seekers from Tunisia may be explained by the more recent political changes [1]. But we were not able to find a clear explanation of why we observed a particularly high number of Somali asylum seekers and especially low numbers of Nigerian asylum seekers compared with the national statistics. It can only be speculated that Nigerian asylum seekers may more often arrive in Switzerland from the West through Spain and France [16] and are therefore more often present in the Western (French speaking) parts of Switzerland, whereas Somali asylum seekers may more often arrive from the East or the South via Italy [17] and may therefore be more often present in the central parts of Switzerland.

Generally asylum seekers and refugees are at increased risk of suffering from multiple health problems [7, 18]. According to a review by Harris and Telfer, one in six refugees has a physical health problem severe enough to prevent them from going about their daily life [8]. Asylum seekers may suffer from the physical sequels of torture or other violent trauma, which may not have received adequate medical attention in their countries of origin [8]. In addition, it is well known that the asylum process itself, the uncertainty of whether the application may be refused and the detention-like living conditions have a high impact on the physical and especially the mental health of asylum seekers [9, 11, 14, 19]. Furthermore, a study by Cooke et al. on 199 East African children found that although $63 \%$ of parents reported medical consultations since arrival, $77 \%$ of this group reported outstanding, unaddressed health problems [20]. The study identified several factors which made healthcare access and treatment difficult for African asylum seekers: unavailability of interpreters, lack of information on where to find health services and the failure of health care providers to understand their cultural needs [20]. Another specific feature of African patients are multiple accompanying family members, friends or supporters, which can challenge emergency department staff, but who are needed 
for a successful patient-physician interaction. Physician, nursing staff and hospital management should be aware of these difficulties and make sure that, the patients are appropriately managed and supported and that follow-up appointments are made when the patient is discharged from the emergency department. Our hospital is currently setting up a special clinic, with longer "slots" and interculturally trained physicians and nursing staff.

Only a few studies have recorded the actual numbers and the distribution of the health problems suffered by African asylum seekers. A study by Bischoff et al. on a population with mixed countries of origin found medical problems in about $35 \%$ of all cases [9], a finding that is slightly lower than in our study. A study by Tiong et al. on 258 newly arrived African refugees showed that African asylum seekers often have previously unrecognized health conditions, such as inadequate immunity to diseases which are preventable by vaccination, as well as vitamin D deficiency and gastrointestinal infections [18]. As our study was conducted in an emergency department, we did not routinely screen for diseases not related to the cause of presentation. Therefore general practitioners who follow up the patients have to play a very important role in the health chain for refugees. GPs need to be aware of these health problems and require support in conducting comprehensive health assessments during the early settlement period. These assessments may be assisted by the use of the health assessment guidelines that are available from many sources. If the practitioners do not feel comfortable with such patients, public hospitals and EDs with greater resources should step in and provide support by unhesitatingly accepting referrals [18].

A study by Bischoff et al. found that $8 \%$ of all asylum seekers presented with an injury, a figure which is distinctly different from our results [9]. Even within our emergency department, African asylum seekers present with a high percentage of injury cases relative to the overall admission rates for injury $(135 / 7,000$ or $1.93 \%$ of all injury cases per year). A possible explanation for our findings may be that our emergency department, as the largest in the area, may be more likely to meet the expectations of African asylum seekers, as they generally expect much of Western high-tech medicine such as magnetic resonance tomography $[21,22]$. A further explanation for this phenomenon could also be that African asylum seekers sometimes present with complications from earlier injuries [8] and may therefore-as complex cases-need to be treated in a university hospital.

Compared to other studies, we found remarkably lower rates of psychiatric problems [7, 9, 10]. Even though our numbers increased from 2000 to 2011, they still remain lower than the average figures in other studies with asylum seekers from different countries of origin-with numbers ranging from 25-44 \% [7, 9, 10]. Generally, most of the published figures on the psychiatric problems suffered by asylums seekers are overall figures for all nationalities, so no specific statement on African asylum seekers can be made. The extraordinary low percentage of psychiatric problems in our study could be related to somatization, which is often undetected by the physician $[7,9,10,23]$. Two studies on posttraumatic stress suffered by Somali refugees found especially high levels of somatization in this population $[12,24]$. For example, Pavlish et al. found that Somali culture does not dichotomize between body and mind [25], a view that supports the expression of mental pain as somatic symptoms [22-24]. Another important reason why somatization may be undetected may also be that-as Somali women reported-the health services in the home countries did not generally address psychological distress as a disease and that they therefore feared being labelled as mentally ill [25]. Westermeyer et al. tried to establish a screening score to detect posttraumatic stress symptoms in Somali refugees [12]. They found that if two or more of the following clinical symptoms-headache, appetite change, dizziness and sleep problems-occurred, posttraumatic stress is likely in $40 \%$ of all cases and should lead to further investigations [12]. Overall, health care professionals working in non-psychiatric primary health care units should be attentive when confronted with patients from foreign cultural backgrounds presenting with unexplainable somatic symptoms [23].

\section{Limitations}

Our study has some limitations. We did not evaluate data from other groups of asylum seekers. Therefore we cannot make a comparison between African asylum seekers and other groups of asylum seekers, for example from the Middle East or Southern Europe. Furthermore, we did not compare our population with African patients with a resident permit, so we cannot draw any conclusion as to whether the figures we detected are specific for African asylum seekers or the African population in Switzerland.

Furthermore, as our study was conducted retrospectively, no standardized data were obtained. Data were sometimes incomplete and therefore not available for further evaluation. Moreover, the data were partially extracted from narrative comments, so that misinterpretation cannot be excluded.

As patients $>16$ years are treated in the same hospital in a different emergency department, no information about their healthcare problems is available.

\section{Conclusion}

In general, knowledge of African asylum seekers and their healthcare problems is scarce. The increasing numbers of African asylum seekers being admitted to our emergency departments do not represent an actual increase in the health care problems of African asylum seekers. Healthcare problems of African asylum seekers do not only result from the lack of health care services in the country of origin or the exhausting journey to Swit- 
zerland, but also involve the asylum procedure itself. The causes of presentation are manifold. The treatment of African asylum seekers is challenging for the medical team involved due to cultural and linguistic differences. African asylum seekers are especially vulnerable for somatization, a fact which health care professionals should be aware of. The introduction of simple screening scores for postmigration stress should be a key priority in providing more focused treatment.

To the best of our knowledge, this is the only study examining emergency department use by African asylum seekers in Central Europe. Further studies on this topic are essential and encouraged. Also further studies on the living conditions of asylum seekers and their relation to health care problems should be conducted.

\section{Acknowledgments}

The authors wish to thank Beat Baeriswyl of the Federal Agency of Immigration.

\section{Authors' contributions}

Acquisition of data: Graf

Analysis and interpretation of data: Pfortmüller, Graf Drafting of the manuscript: Pfortmüller, Exadaktylos Critical revision of the manuscript for important intellectual content: Tabarra, Lindner, Zimmermann, Exadaktylos

Administrative, technical and material support: Zimmermann, Exadaktylos

Study supervision: Exadaktylos

Dr Exadaktylos had full access to all data in the study and takes responsibility for the integrity of the data and the accuracy of the data analysis.

\section{Conflict of Interest}

The authors declare that there is no actual or potential conflict of interest in relation to this article.

\section{References}

1. United Nations High Commissioner for Refugees (UNHCR). 2009. Global Trends: refugees, asylum-seekers, returnees, internally displaced and stateless persons. Country Data Sheets 2010.

2. Hatton TJ. Seeking asylum in Europe. In: Economic Policy April 2004, editor. Great Britain: Australian National University and University of Essex; 2004. pp. 5-62.

3. Failed State Index. http://www.foreignpolicy.com/failedstates. Accessed 26 Dec. 2011.

4. Somalia Tops the Failed States Index. http://www.fundforpeace.org/global/?q=node/123. Accessed 26 Dec. 2011.

5. Personen im Asylprozess. http://www.bfs.admin.ch/bfs/ portal/de/index/themen/01/07/blank/key/01/04.html. Accessed 11 Dec. 2011

6. Baeriswyl B. Statistik zu afrikanischen Asylsuchenden. In: Migration Bf, editor. Bern; 2011.

7. Maier T, Schmidt M, Mueller J. Mental health and healthcare utilization in adult asylum seekers. Swiss Med Wkly. 2010;140:w13110.
8. Harris MF, Telfer BL. The health needs of asylum seekers living in the community. Med J Aust. 2001;175(11-12):589-592.

9. Bischoff A, Denhaerynck K, Schneider M, Battegay E. The cost of war and the cost of healthcare-an epidemiological study of asylum seekers. Swiss Med Wkly. 2011;141:w13252.

10. Laban CJ, Komproe IH, Gernaat HB, de Jong JT. The impact of a long asylum procedure on quality of life, disability and physical health in Iraqi asylum seekers in the Netherlands. Soc Psychiatry Psychiatr Epidemiol. 2008;43(7):507-515.

11. Gerritsen AA, Bramsen I, Deville W, et al. Use of health care services by Afghan, Iranian, and Somali refugees and asylum seekers living in the Netherlands. Eur J Public Health. 2006;16(4):394-399.

12. Westermeyer JJ, Campbell R, Lien R, et al. HADStress: a somatic symptom screen for posttraumatic stress among Somali refugees. Psychiatr Serv (Washington, DC). 2010;61(11):1132-1137.

13. Nickerson A, Steel Z, Bryant R, Brooks R, Silove D. Change in visa status amongst Mandaean refugees: relationship to psychological symptoms and living difficulties. Psychiatry Res. 2011;187(1-2):267-274.

14. Renner W, Salem I. Post-traumatic stress in asylum seekers and refugees from Chechnya, Afghanistan, and West Africa: gender differences in symptomatology and coping. Int J Soc Psychiatry. 2009;55(2):99-108.

15. O'Donnell CA, Higgins M, Chauhan R, Mullen K. "They think we're OK and we know we're not". A qualitative study of asylum seekers' access, knowledge and views to health care in the UK. BMC Health Serv Res. 2007;7:75.

16. Agyemang C, Goosen S, Anujuo K, Ogedegbe G. Relationship between post-traumatic stress disorder and diabetes among 105,180 asylum seekers in the Netherlands. Eur J Public Health. 2011.

17. Moret Joëlle BS, Efionayi-Mäder Denise. Somali refugees in Switzerland: strategies of exile and policy responses. Neuchâtel: Swiss Forum For Migration And Population Studies (SFM); 2006.

18. Tiong AC, Patel MS, Gardiner J, et al. Health issues in newly arrived African refugees attending general practice clinics in Melbourne. Med J Aust. 2006;185(11-12):602-606.

19. Steel Z, Momartin S, Silove D, et al. Two year psychosocial and mental health outcomes for refugees subjected to restrictive or supportive immigration policies. Soc Sci Med. 2011;72(7):1149-1156.

20. Cooke R, Murray S, Carapetis J, et al. Demographics and utilisation of health services by paediatric refugees from East Africa: implications for service planning and provision. Aust Health Rev. 2004;27(2):40-45.

21. O'Donnell CA, Higgins M, Chauhan R, Mullen K. Asylum seekers' expectations of and trust in general practice: a qualitative study. Br J Gen Pract. 2008;58(557):e1-11.

22. DeShaw PJ. Use of the emergency department by Somali immigrants and refugees. Minn Med. 2006;89(8):42-45.

23. Schubert CC, Punamaki RL. Mental health among torture survivors: cultural background, refugee status and gender. Nord J Psychiatry. 2011;65(3):175-182.

24. Bentley JA, Thoburn JW, Stewart DG, Boynton LD. The indirect effect of somatic complaints on report of posttraumatic psychological symptomatology among Somali refugees. J Trauma Stress. 2011;24(4):479-482.

25. Pavlish CL, Noor S, Brandt J. Somali immigrant women and the American health care system: discordant beliefs, divergent expectations, and silent worries. Soc Sci Med. 2010;71(2):353-361. 